\title{
PARAMENTAÇÃO E DESPARAMENTAÇÃO: PROCEDIMENTOS PARA PREVENIREM CONTAMINAÇÃO PELO NOVO CORONAVÍRUS
}

\section{REVISÃO INTEGRATIVA}

LOPES, Lorena Machado 1

DIAS, Sonia Maria ${ }^{2}$

LOPES, Lorena Machado. DIAS, Sonia Maria. Paramentação e desparamentação: Procedimentos para prevenirem contaminação pelo novo coronavírus. Revista Científica Multidisciplinar Núcleo do Conhecimento. Ano 05, Ed. 12, Vol. 05, pp. 154178. Dezembro de 2020. ISSN: 2448-0959, Link de acesso: https://www.nucleodoconhecimento.com.br/saude/paramentacao

\section{RESUMO}

Este estudo traçou os seguintes objetivos: identificar divergências e similaridades nas orientações/determinações elencadas na literatura sobre paramentação e desparamentação e sumarizar o consenso para os passos adequados para a realização dos procedimentos elencados com base nos textos literários. Buscou-se responder à questão problema que diz respeito a: quais são os procedimentos operacionais evidenciados na literatura, brasileira e internacional, orientados para a paramentação e desparamentação, a fim de evitar a infecção do profissional de saúde pelo novo coronavírus. A metodologia adotada foi de revisão sistemática da literatura do tipo integrativa. Para a coleta de informações foi utilizada a base de dados da Biblioteca Virtual em Saúde e incluído as plataformas eletrônicas de órgãos públicos. Foi utilizado o modelo adaptado ao método prisma para seleção da literatura identificada, sendo delimitada em publicações do ano de 2020 por razão da

${ }^{1}$ Enfermeira, Graduanda do Programa de Residência Multiprofissional em Atenção Hospitalar.

2 Doutora em Enfermagem. 
declaração, neste ano, da pandemia pelo novo coronavírus pela Organização Mundial de Saúde. Os resultados mostraram um conjunto diversificado de equipamentos de proteção individual necessários para a proteção de profissionais de saúde e existência de passos similares para os procedimentos de paramentação e desparamentação. Para as considerações finais foi sumarizado a ordem sequencial para a execução dos procedimentos investigados, a ser adotada pelo profissional de saúde para prevenir a contaminação, em especial aqui, pelo novo coronavírus.

Palavras-Chave: Coronavírus, profissionais de saúde, controle de infecções.

\section{INTRODUÇÃO}

A pandemia evidenciada pela ação do novo coronavírus, que causa a doença denominada de COVID-19 (Corona Vírus Disease), teve o primeiro caso oficial na China em dezembro de 2019, construindo uma rota de transmissão do vírus, ainda que desconhecida, mas que se espalhou para diversos países dos continentes. É uma emergência de saúde pública global, que alterou a rotina da vida da população ao redor do mundo. A alteração no modo de viver das pessoas é decorrente da alta transmissibilidade do vírus trazendo, por vezes, como consequência, sequelas para pessoas recuperadas da COVID-19 e perdas de vidas em situações de quadros clínicos severos (VELAVAN, 2020).

O número de casos da doença muda diariamente sendo possível detectá-lo em tempo real. Do mês de março de 2020, quando foi reconhecida a presença de pandemia pela Organização Mundial de Saúde - OMS, até o mês de setembro do ano em curso, órgão público aponta os dados a seguir. O Boletim Epidemiológico Especial do Ministério da Saúde (referente à Semana Epidemiológica (SE) 36 - período de 30/08/20 a 05/09/20) traz um total de 26.640 .898 casos confirmados de COVID-19 no mundo. Os Estados Unidos foi o país com o maior número de casos acumulados (6.201.726), seguido pelo Brasil (4.123.000), Índia (4.023.179), Rússia (1.015.105) e Peru (676.848). Em relação aos óbitos, e até essa mesma data, a estatística mostra um total de 874.967 no mundo, sendo os Estados Unidos o país com maior número 
acumulado de óbitos (187.765), seguido do Brasil (126.203), Índia (69.561), México (66.851) e Reino Unido (41.537) (MS, 2020). Isso indica a magnitude de transmissibilidade do novo coronavírus e as consequências da COVID-19.

Em virtude da COVID-19 ser uma doença nova, e até o momento, não existir uma vacina eficaz disponível, todas as pessoas estão susceptíveis à infecção, em especial os profissionais de saúde visto que se encontram na linha de frente de atendimento de pacientes infectados (ANVISA, 2020a). Segundo dados fornecidos pelo Conselho Federal de Enfermagem (COFEN), até meados de setembro de 2020 foram reportados 38.750 casos de infecção pelo novo coronavírus em profissionais de enfermagem, e dentre esses casos, 395 evoluíram para óbito (COFEN, 2020). Esses números representam o reflexo do risco laboral a que os profissionais da área da saúde são submetidos, especialmente diante de uma nova doença.

Os profissionais durante o desempenho de suas atividades, além de expostos ao risco de infecção pelo novo coronavírus, estão susceptíveis ao estresse associado à prestação de assistência direta a pacientes suspeitos ou confirmados de COVID-19. Um estudo de corte transversal avaliou 16.630 profissionais de saúde quanto ao estado mental e qualidade do sono e demonstrou depressão em 14\%-15\%; ansiedade em 12\%-24\%; 30\%-39\% com distúrbio psicológico e 8\%-60\% com distúrbios do sono (ANVISA, 2020a).

A preocupação relativa à segurança/bem estar dos profissionais da área da saúde se dá principalmente devido a dois fatores, o primeiro é que o afastamento de um grande número de colaboradores do serviço diminui a capacidade do mesmo, gerando uma sobrecarga ainda maior no sistema de saúde. Além disso, uma vez infectados pela doença, e no caso de não diagnosticados e isolados, esses profissionais podem atuar como vetores na disseminação do vírus para outros pacientes, familiares e para a comunidade em geral (VERBEEK et al, 2020).

De acordo com a rede global de especialistas da OMS a transmissão do novo coronavírus ocorre principalmente por meio de gotículas respiratórias (expelidas 
durante a fala, tosse ou espirro) de pessoas infectadas para outras pessoas que estão em contato próximo, através do contato direto com a pessoa infectada ou por contato com objetos e superfícies contaminados. Além disso, têm-se acumulado evidências científicas do potencial de transmissão da COVID-19, sobretudo, por inalação do vírus através de partículas de aerossóis geradas durante procedimentos hospitalares, como por exemplo, durante a manipulação direta da via aérea, intubação e extubação de pacientes, em procedimentos de aspiração (ANVISA, 2020a).

O uso de equipamentos de proteção individual (EPIs) é o método de controle mais indicado para prevenir a propagação da infecção durante a assistência à saúde, entretanto, é apenas uma das medidas de prevenção e controle, retendo benefícios limitados, necessitando ser associado às estratégias primárias de prevenção, como higiene das mãos frequente, limpeza de rotina e desinfecção do ambiente e superfícies, distanciamento social, entre outras (WHO, 2020b).

Para que esses equipamentos sejam eficazes na diminuição do risco de infecção devem ser observadas de forma criteriosa a indicação de uso, manejo, retirada, descarte e entre outras especificidades, sempre considerando as evidências científicas atuais disponíveis e as orientações dos órgãos de saúde. É imprescindível que seja ofertado aos profissionais da área da saúde treinamentos e atividades de educação continuada sobre o novo coronavírus e as diretrizes de prevenção e controle de infecção, principalmente acerca do manejo correto dos EPIs e suas especificações (HOUGHTON et al, 2020).

Considerando a importância dos equipamentos de proteção individual no contexto da biossegurança dos profissionais de saúde, esse estudo busca responder a seguinte questão: Quais são os procedimentos operacionais evidenciados na literatura, brasileira e internacional, orientados para a paramentação e desparamentação, a fim de evitar a infecção do profissional de saúde pelo novo coronavírus?

Para responder essa questão este estudo traçou o(s) seguinte(s) objetivo(s): 
Identificar divergências e similaridades nas orientações/determinações elencadas na literatura sobre paramentação e desparamentação.

Sumarizar o consenso para os passos dos procedimentos de paramentação e desparamentação com base nos textos selecionados para a revisão integrativa.

\section{METODOLOGIA}

Trata-se de uma revisão sistemática da literatura do tipo integrativa que utilizou de métodos explícitos e sistemáticos descritos por Souza, Silva e Carvalho que possui a seguinte estrutura: elaboração da pergunta norteadora; busca ou amostragem na literatura; coleta de dados; análise crítica dos estudos incluídos; discussão dos resultados; apresentação da revisão integrativa (SOUZA, 2010).

Elaborou-se a seguinte questão de pesquisa já mencionada anteriormente: Quais são os procedimentos operacionais evidenciados na literatura, brasileira e internacional, orientados para a paramentação e desparamentação, a fim de evitar a infecção do profissional de saúde pelo novocoronavírus?

A opção pelo método sistemático de revisão integrativa visa elaborar análise acerca do conhecimento construído e divulgado nos diversos veículos para publicações, e esse saber materializado no passado, pode gerar novos conhecimentos para o desenvolvimento da ciência.

A análise dos dados buscou determinar quais os procedimentos operacionais orientados para a paramentação e desparamentação do profissional que presta assistência às pessoas com suspeita e/ou confirmação de COVID -19, a fim de evitar a contaminação pelo novo coronavírus. Os resultados foram confrontados entre si, com 0 intuito de identificar divergências e similaridades nas orientações/determinações descritas nos textos publicados.

A busca na literatura foi realizada entre o dia 20 do mês de julho ao dia 10 do mês de setembro de 2020. Foram incluídos na busca as literaturas publicadas no ano de 2020 , 
por ser a data em que foi declarada a pandemia do novo coronavírus pela Organização Mundial de Saúde (OMS/OPAS, 2020). A Biblioteca Virtual em Saúde (BVS) foi utilizada de base para a busca de dados por ser de abrangência no campo da saúde.

\section{CRITÉRIOS UTILIZADOS PARA A INCLUSÃO DOS ESTUDOS NESTA PESQUISA}

Assim como o nome traz, o novo coronavírus é um vírus que surgiu recentemente e teve uma disseminação mundial rápida, o que resultou na atual pandemia em que vivemos. Apesar dos esforços mundiais, ainda é escasso o conhecimento acerca de algumas variáveis do vírus, limitando o desenvolvimento de estudos.

Considerando essa limitação referida e o(s) objetivo(s) proposto(s) neste estudo, foram incluídos somente artigos de revisão sistemática da literatura. Além disso, uma vez que a intenção deste estudo, de forma geral, é discorrer sobre os procedimentos operacionais voltados para a biossegurança do profissional de saúde que lida com usuários de serviços hospitalares suspeitos e/ou confirmados da COVID-19, julgou-se como necessária a inclusão de publicações oficiais de diretrizes de órgãos de saúde do Brasil e internacionais.

\section{CRITÉRIOS UTILIZADOS PARA A EXCLUSÃO DOS ESTUDOS NESTA PESQUISA}

Os estudos que não contemplavam os descritores elencados foram desconsiderados. Também desconsiderados aqueles que, apesar de atenderem os descritores, não se encontravam disponíveis na íntegra, e os que não dispunham de acesso livre de pagamento para a leitura, dissertações e teses.

\section{MÉTODO DE BUSCA PARA IDENTIFICAÇÃO DE PUBLICAÇÕES ELEGÍVEIS}

\section{BUSCA ELETRÔNICA EM PERIÓDICOS}


Realizou-se uma pesquisa sistemática da literatura para identificar todas as publicações sistemáticas qualitativas que poderiam ser consideradas elegíveis para inclusão neste trabalho. A busca efetuada na Biblioteca Virtual em Saúde (BVS) se deu por meio dos descritores previamente selecionados, de acordo com a plataforma dos Descritores em Ciências em Saúde (DeCS) culminando com os seguintes termos escolhidos: Coronavírus, Profissionais de Saúde e Controle de Infecções.

O rastreio do conhecimento construído foi orientado por um fluxo, de modo a evidenciar aqueles textos que se enquadravam no tema a ser estudado. Cabe esclarecer que o método Preferred Reporting Items for Systematic Reviews and MetaAnalyses (PRISMA) serviu para orientar a organização da busca pela produção científica (GALVÃO, 2015).

Foram realizadas duas estratégias de busca no periódico, sendo a primeira da seguinte forma:

- Descritores utilizados na busca: Coronavírus AND "Profissionais de saúde".

- Filtros selecionados:

Idiomas: português, inglês e espanhol;

Ano de publicação: 2020;

Tipo de documento: artigo completo disponível.

A estratégia está descrita no fluxograma I (Figura 1).

Figura 1: Fluxograma do processo de seleção dos estudos I, adaptado do PRISMA. 


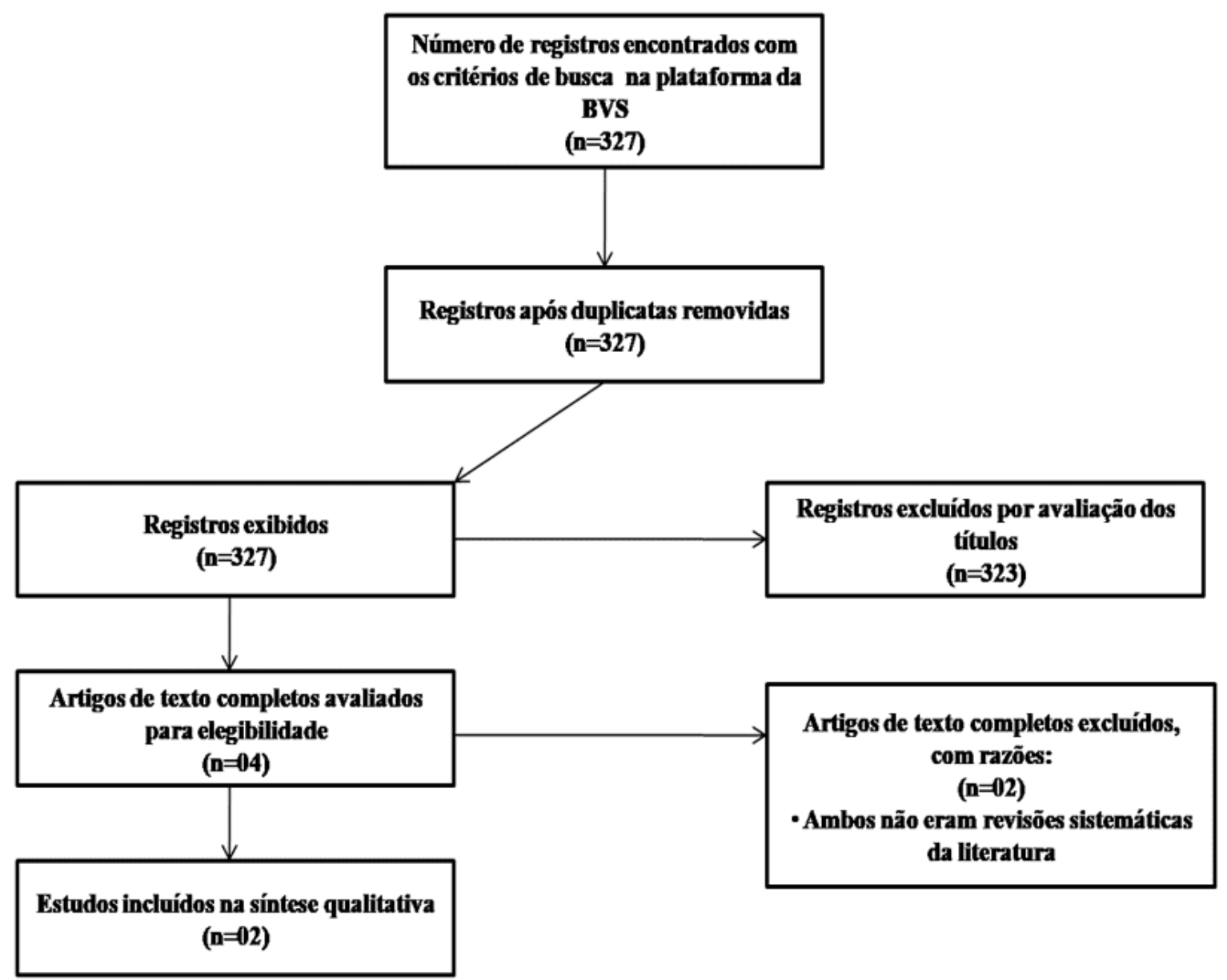

A segunda estratégia de busca de pesquisa no periódico considerou:

- Descritores: Coronavírus AND "Profissionais de saúde" AND "Controle de infecções".

- Filtros selecionados:

Idiomas: português, inglês e espanhol;

Ano de publicação: 2020;

Tipo de documento: artigo completo disponível.

A segunda estratégia está descrita no fluxograma II (Figura 2). 
Figura 2: Fluxograma do processo de seleção dos estudos II, adaptado do PRISMA.

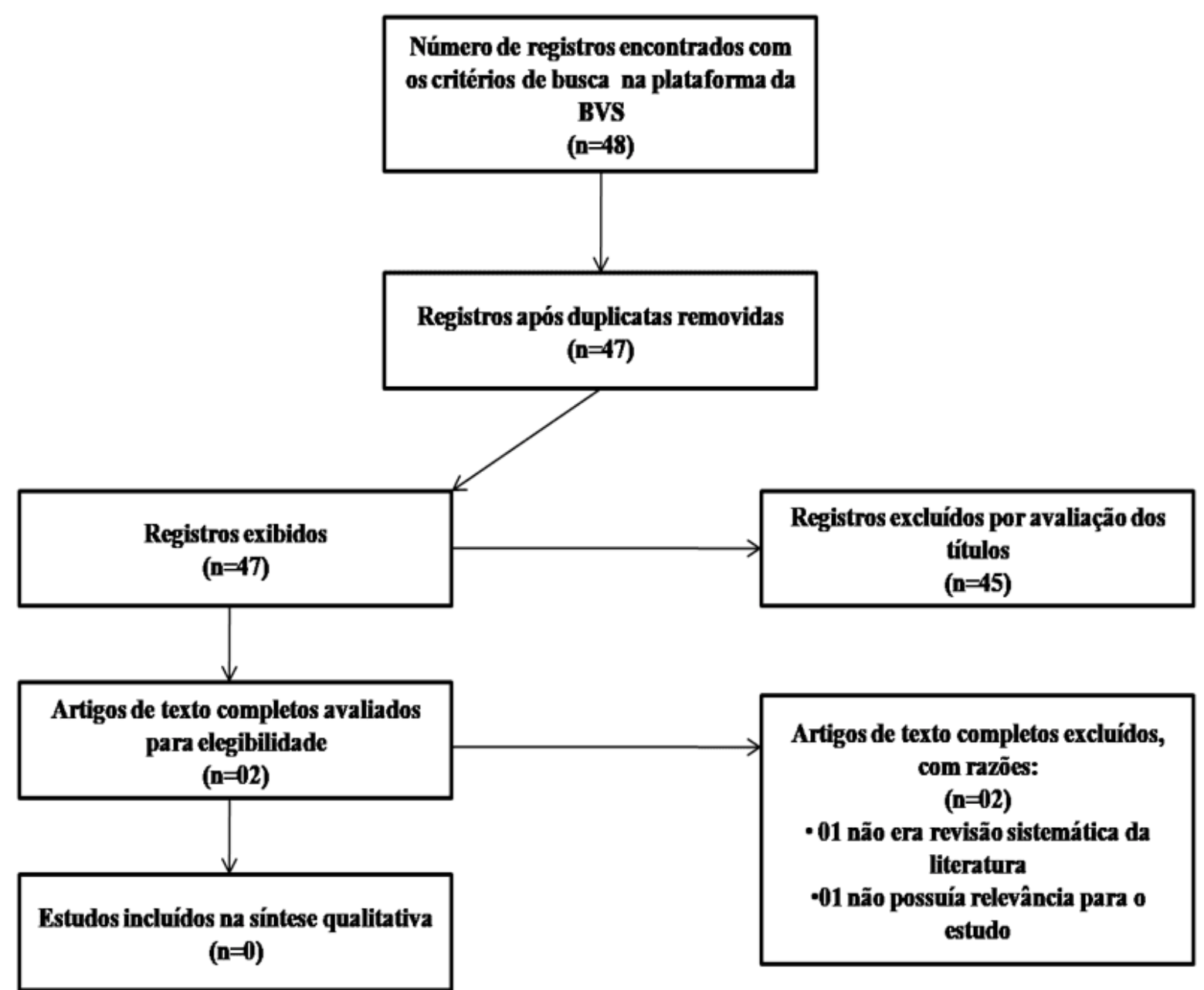

\section{BUSCA ELETRÔNICA NAS PLATAFORMAS DOS ÓRGÃOS DE SAÚDE}

Foram incluídos neste estudo publicações oficiais encontradas nos sites dos órgãos de saúde considerados referência nacional e internacional no combate ao novo coronavírus, são eles:

- Centers for Disease Control and Prevetion (CDC)

- Organização Mundial de Saúde (OMS)

- Agência Nacional de Vigilância Sanitária (ANVISA) 
- Associação de Medicina Intensiva Brasileira (AMIB)

- Ministério da Saúde (MS)

A seleção dos documentos foi realizada a partir de três etapas principais:

1. Avaliação primária do título do documento:

O título possui relação com o novo coronavírus e/ou o uso de equipamentos de proteção individual (EPIs)?

2. Avaliação secundária:

Análise do título, resumo e/ou sumário do documento: esses itens trazem informações acerca dos profissionais de saúde e/ou da prevenção e controle de infecções?

Ano de publicação: foi publicado em 2020?

3. Avaliação terciária:

Após essa primeira triagem os documentos selecionados foram lidos na íntegra, e utilizou-se o seguinte critério para inclusão:

O conteúdo do documento é pertinente ao objeto de estudo deste trabalho? A estratégia está descrita no fluxograma III (Figura 3).

Figura 3: Fluxograma do processo de seleção das publicações III, adaptado do PRISMA. 


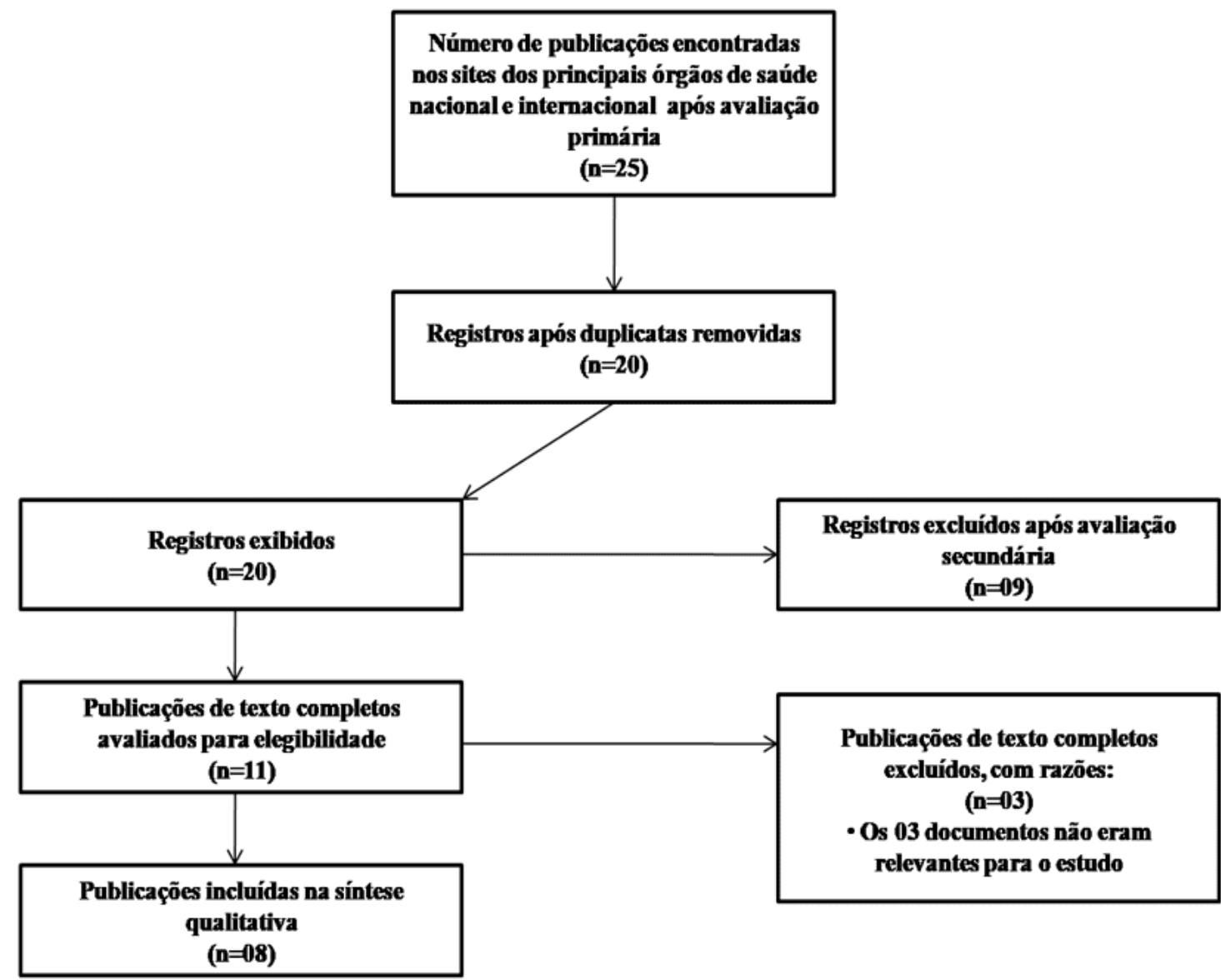

Foram identificados 371 artigos na base de dados, sendo excluídos um total de 368 por não atenderem aos critérios de inclusão e/ou não responderem à questão norteadora da pesquisa e as duplicatas também foram removidas. Os 06 estudos selecionados foram submetidos à leitura na íntegra e após este momento, excluiu-se 04 artigos, de acordo com os critérios de exclusão estabelecidos. Elegeram-se 02 artigos para compor a revisão integrativa. Referentes às orientações de órgãos públicos, fez parte do conjunto de textos selecionados o total de 08 .

\section{RESULTADOS}

\section{ANÁLISE CRÍTICA DOS ESTUDOS INCLUÍDOS}

Tomando-se por base os critérios de inclusão e exclusão, somaram-se 10 referências, simbolizadas pela letra $\mathrm{R}$ acompanhada por um número conforme mostra o quadro a seguir. Os textos selecionados foram agrupados no nível IV ${ }^{0}$ da classificação de 
Souza, Silva e Carvalho para a prática baseada em evidência, pois abrange estudos de abordagem qualitativa. (SOUZA, 2010). A compilação sintética desses documentos se encontra no Quadro 1, caracterizado pela referência numerada, autores e ano de publicação, país de origem do texto, título e síntese dos resultados.

Quadro 1 - Estudos encontrados conforme autoria e ano de publicação, país, título, síntese dos resultados

\begin{tabular}{|c|c|c|c|c|c|}
\hline $\begin{array}{l}\text { Referê } \\
\text { ncia }\end{array}$ & $\begin{array}{l}\text { Autores } \\
\text { e ano }\end{array}$ & País & Título & & Síntese dos resultados \\
\hline R1 & $\begin{array}{l}\text { Centers } \\
\text { for } \\
\text { Disease } \\
\text { Control } \\
\text { and } \\
\text { Preventi } \\
\text { on, } 2020\end{array}$ & $\begin{array}{l}\text { Esta } \\
\text { dos } \\
\text { Unid } \\
\text { os da } \\
\text { Amér } \\
\text { ica }\end{array}$ & $\begin{array}{l}\text { Using } \\
\text { Protective } \\
\text { (PPE) }\end{array}$ & $\begin{array}{l}\text { Personal } \\
\text { Equipment }\end{array}$ & $\begin{array}{l}\text { Este documento orienta } \\
\text { como os profissionais da } \\
\text { saúde devem realizar a } \\
\text { colocação e a retirada dos } \\
\text { EPIs: } \\
\text { Colocação/paramentação: } \\
\text { 1ํ identificação e reunião } \\
\text { dos EPIs necessários; } 2^{\circ} \\
\text { higiene das mãos; } 3^{\circ} \\
\text { avental/ capote; } 4^{\circ} \text { máscara } \\
\text { cirúrgica ou N95/PFF2; } 5^{\circ} \\
\text { protetor facial ou óculos de } \\
\text { proteção; } 6{ }^{\circ} \text { luvas; } 7^{\circ} \text { o } \\
\text { profissional agora pode } \\
\text { entrar no quarto do } \\
\text { paciente. }\end{array}$ \\
\hline & & & & & $\begin{array}{l}\text { Retirada/desparamentação } \\
:\end{array}$ \\
\hline
\end{tabular}




\begin{tabular}{|c|c|c|c|c|}
\hline & & & & $\begin{array}{l}1^{\circ} \text { luvas; } 2^{\circ} \text { avental/capote; } \\
3^{\circ} \text { o profissional agora pode } \\
\text { saír do quarto do paciente; } \\
4^{\circ} \text { higiene das mãos; } 5^{\circ} \\
\text { proteção facial ou óculos de } \\
\text { proteção; } 6^{\circ} \text { máscara } \\
\text { cirúrgica ou N95/PFF2; } 7^{\circ} \\
\text { Higiene das mãos. }{ }^{*} \text { As } \\
\text { instalações } \\
\text { implementam a reutilização } \\
\text { ou uso prolongado de EPI } \\
\text { devem ajustar seus } \\
\text { procedimentos } \\
\text { colocação e retirada para } \\
\text { acomodar essas práticas. }\end{array}$ \\
\hline R2 & $\begin{array}{l}\text { World } \\
\text { Health } \\
\text { Organiz } \\
\text { ation, } \\
2020\end{array}$ & $\begin{array}{l}\text { Esta } \\
\text { dos } \\
\text { Unid } \\
\text { os da } \\
\text { Amér } \\
\text { ica }\end{array}$ & $\begin{array}{l}\text { Rational use of personal } \\
\text { protective equipment for } \\
\text { coronavirus disease } \\
\text { (COVID-19) and } \\
\text { considerations during } \\
\text { severe shortages }\end{array}$ & $\begin{array}{l}\text { O documento traz três } \\
\text { estratégias principais para } \\
\text { otimizar a disponibilidade } \\
\text { dos EPIs: } \\
1^{\circ} \text { Minimizar a necessidade } \\
\text { de uso desses } \\
\text { equipamentos por meio de } \\
\text { estratégias como a } \\
\text { utilização de telemedicina } \\
\text { para avaliação inicial de } \\
\text { pacientes suspeitos, } \\
\text { redução do número de } \\
\text { profissionais nas áreas de } \\
\text { risco, simplificação do fluxo } \\
\text { de trabalho etc.; }\end{array}$ \\
\hline
\end{tabular}




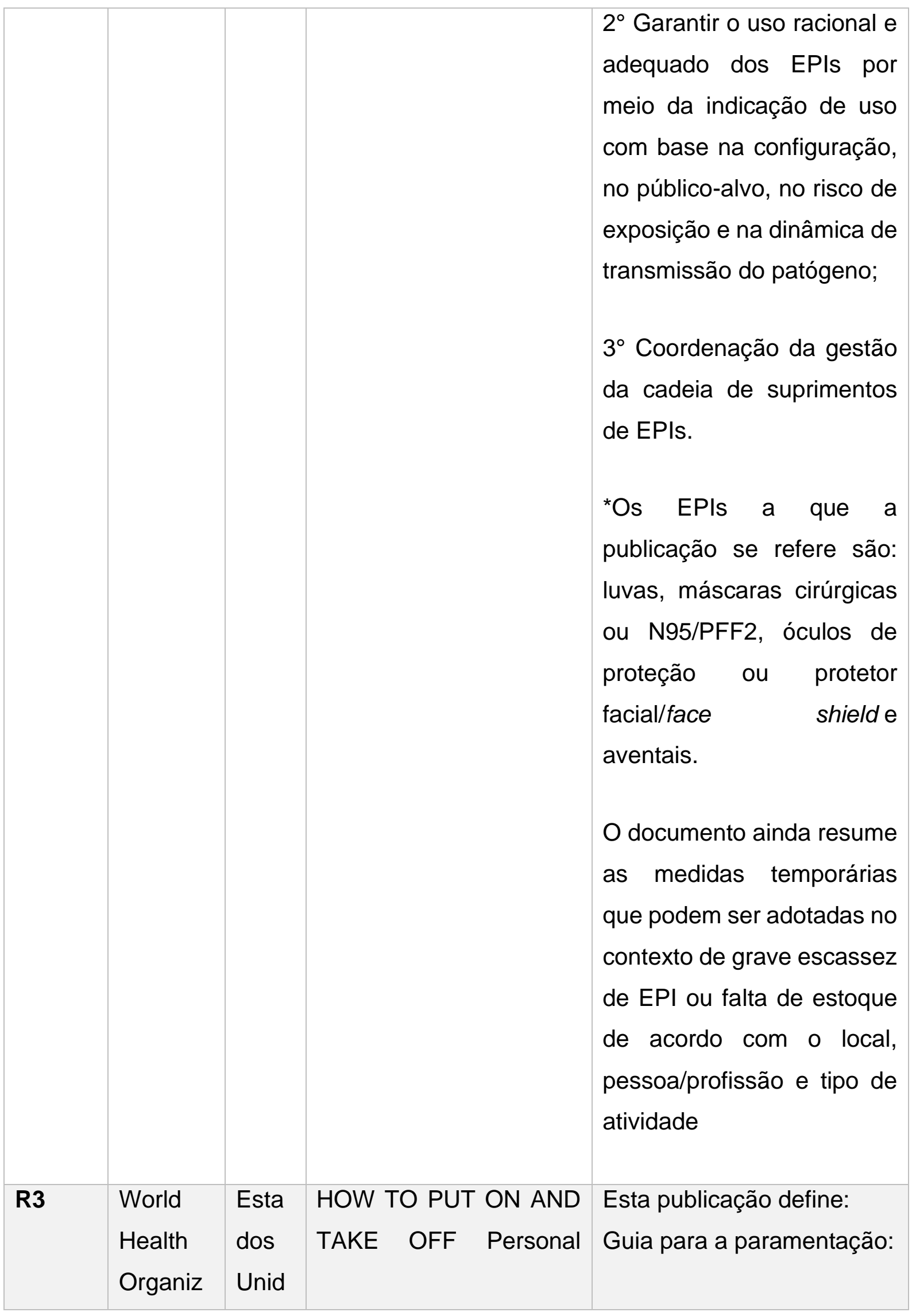




\begin{tabular}{|c|c|c|c|c|}
\hline & $\begin{array}{l}\text { ation, } \\
2020\end{array}$ & $\begin{array}{l}\text { os da } \\
\text { Amér } \\
\text { ica }\end{array}$ & $\begin{array}{l}\text { Protective Equipment } \\
\text { (PPE) }\end{array}$ & $\begin{array}{l}1^{\circ} \text { higiene das mãos com } \\
\text { água e sabão ou álcool; } 2^{\circ} \\
\text { colocação do } \\
\text { avental/capote; } \\
\text { colocação da máscara } \\
\text { cirúrgica ou N95/PFF2; } 4^{\circ} \\
\text { colocação da face shield ou } \\
\text { óculos de proteção; } 5^{\circ} \\
\text { colocação das luvas. } \\
\text { Guia para } \\
\text { desparamentação: } \\
1^{\circ} \text { retirada das luvas; } 2^{\circ} \\
\text { retirada do avental/capote; } \\
3^{\circ} \text { higiene das mãos; } 4^{\circ} \\
\text { remoção da face shield ou } \\
\text { óculos de proteção; } 5^{\circ} \\
\text { retirada da máscara; } 6^{\circ} \\
\text { higiene das mãos. }\end{array}$ \\
\hline R4 & $\begin{array}{l}\text { Centers } \\
\text { for } \\
\text { Disease } \\
\text { Control } \\
\text { and } \\
\text { Preventi } \\
\text { on, } 2020\end{array}$ & $\begin{array}{l}\text { Esta } \\
\text { dos } \\
\text { Unid } \\
\text { os da } \\
\text { Amér } \\
\text { ica }\end{array}$ & $\begin{array}{l}\text { Interim Infection } \\
\text { Prevention and Control } \\
\text { Recommendations for } \\
\text { Healthcare Personnel } \\
\text { During the Coronavirus } \\
\text { Disease } 2019 \text { (COVID- } \\
\text { 19) Pandemic Infection } \\
\text { Control Guidance }\end{array}$ & $\begin{array}{l}\text { O documento traz como } \\
\text { responsabilidade da } \\
\text { instituição de saúde a } \\
\text { definição e descrição } \\
\text { de políticas } \\
\text { procedimentos } \\
\text { relacionados à sequência } \\
\text { segura de colocação e } \\
\text { retirada dos EPls. No caso } \\
\text { de EPI reutilizável a } \\
\text { instituição é também }\end{array}$ \\
\hline
\end{tabular}




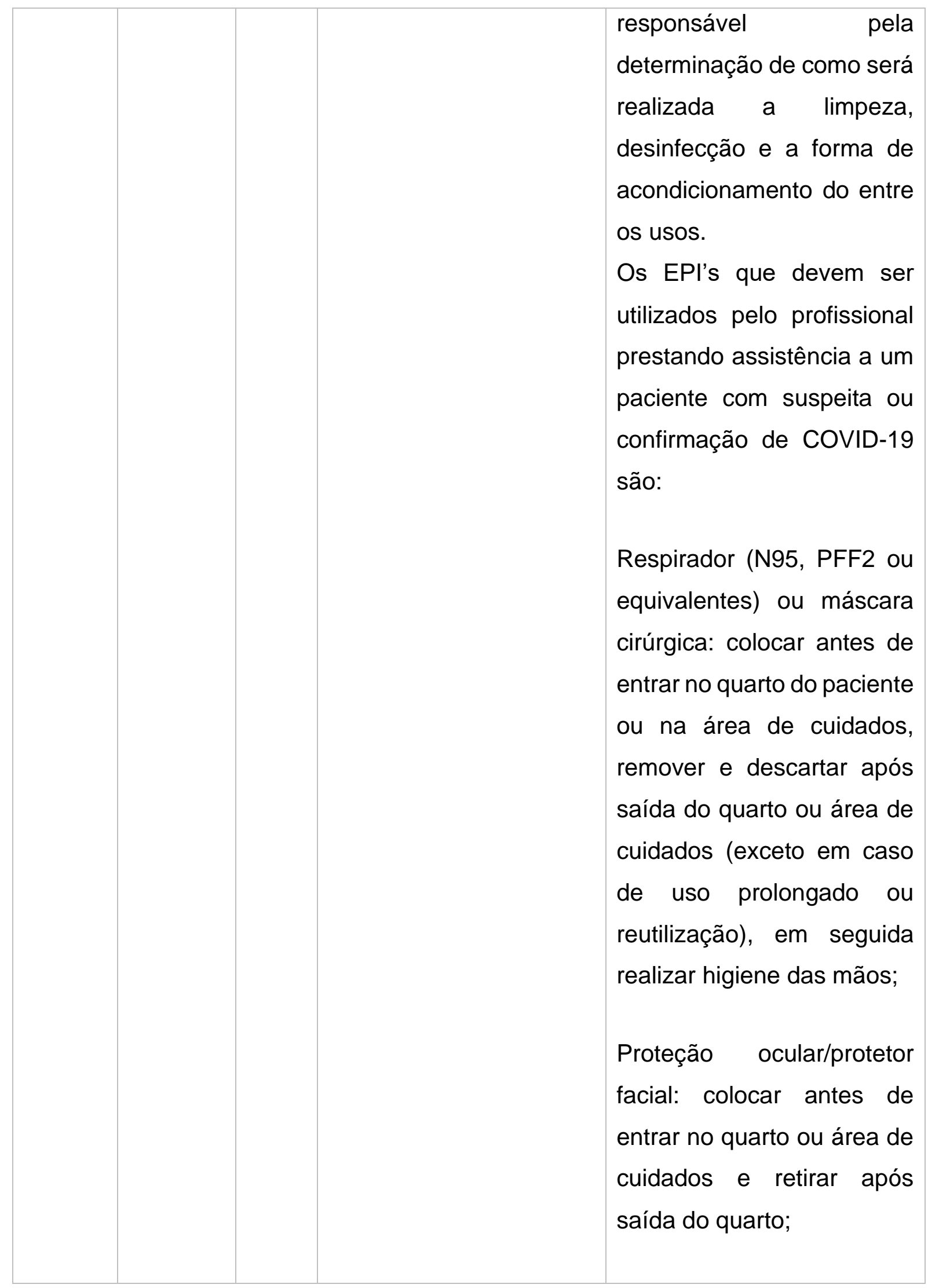




\begin{tabular}{|c|c|c|c|c|}
\hline & & & & $\begin{array}{l}\text { Luvas de procedimento: } \\
\text { devem ser colocadas ao } \\
\text { entrar no quarto ou área de } \\
\text { cuidados, realizar trocas em } \\
\text { caso de rasgo ou } \\
\text { contaminação excessiva. } \\
\text { Retirar e descartar antes da } \\
\text { saída do quarto ou área de } \\
\text { cuidados, com higiene das } \\
\text { mãos imediatamente após; } \\
\text { Avental/capote: colocar } \\
\text { antes da entrada no quarto } \\
\text { ou área de cuidados, } \\
\text { realizar troca em caso de } \\
\text { sujidade importante. A } \\
\text { remoção e o descarte } \\
\text { devem ocorrer antes de } \\
\text { deixar o ambiente. Em caso } \\
\text { de capotes descartáveis } \\
\text { descartá-los no lixo } \\
\text { infectante, se o avental for } \\
\text { de pano deve ser } \\
\text { encaminhado avagem/desinfecção } \\
\text { cada uso a }\end{array}$ \\
\hline R5 & $\begin{array}{l}\text { Centers } \\
\text { for } \\
\text { Disease } \\
\text { Control } \\
\text { and }\end{array}$ & $\begin{array}{l}\text { Esta } \\
\text { dos } \\
\text { Unid } \\
\text { os da } \\
\text { Amér } \\
\text { ica }\end{array}$ & $\begin{array}{l}\text { Interim Operational } \\
\text { Considerations for Public } \\
\text { Health Management of } \\
\text { Healthcare Workers } \\
\text { Exposed to or with } \\
\text { Suspected or Confirmed }\end{array}$ & $\begin{array}{l}\text { Este documento traz } \\
\text { considerações } \\
\text { operacionais para auxiliar } \\
\text { os serviços de saúde no } \\
\text { gerenciamento de } \\
\text { profissionais expostos à }\end{array}$ \\
\hline
\end{tabular}




\begin{tabular}{|c|c|c|}
\hline $\begin{array}{l}\text { Preventi } \\
\text { on, } 2020\end{array}$ & $\begin{array}{l}\text { COVID-19: non-U.S. } \\
\text { Healthcare Settings }\end{array}$ & 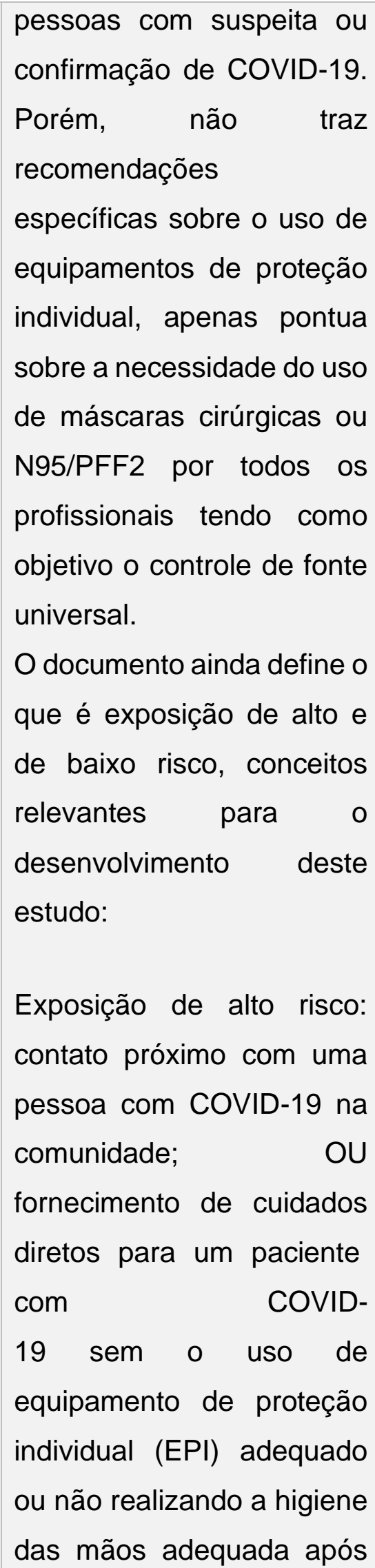 \\
\hline
\end{tabular}




\begin{tabular}{|c|c|c|c|c|}
\hline & & & & $\begin{array}{l}\text { essas interações; OU ter } \\
\text { contato com as secreções } \\
\text { infecciosas de um paciente } \\
\text { com COVID-19 de } \\
\text { ambiente de atendimento } \\
\text { ao paciente contaminado, } \\
\text { sem usar equipamento de } \\
\text { proteção individual (EPI) } \\
\text { adequado ou não realizar a } \\
\text { higiene das mãos } \\
\text { adequada. } \\
\text { Exposição de baixo risco: } \\
\text { contato com uma pessoa } \\
\text { com COVID-19 que não } \\
\text { atendeu aos critérios de } \\
\text { exposição de alto risco (por } \\
\text { exemplo, breves interações } \\
\text { com pacientes COVID-19 } \\
\text { no hospital ou nanidade). }\end{array}$ \\
\hline R6 & $\begin{array}{l}\text { Agência } \\
\text { Nacional } \\
\text { de } \\
\text { Vigilânci } \\
\text { a } \\
\text { Sanitária } \\
\text {, } 2020\end{array}$ & Brasi & $\begin{array}{l}\text { NOTA TÉCNICA № } \\
\text { 12/2020/SEI/GGTES/DI } \\
\text { RE1/ANVISA } \\
\text { Manifestação sobre o } \\
\text { processamento } \\
\text { (reprocessamento) de } \\
\text { Equipamentos de } \\
\text { Proteção Individual } \\
\text { (EPIs) }\end{array}$ & $\begin{array}{l}\text { Este arquivo não traz } \\
\text { recomendações } \\
\text { específicas sobre o } \\
\text { processo de paramentação } \\
\text { e desparamentação, mas } \\
\text { aborda o reprocessamento } \\
\text { de equipamentos de } \\
\text { proteção individual, } \\
\text { temática esta relevante } \\
\text { para o processo de }\end{array}$ \\
\hline
\end{tabular}




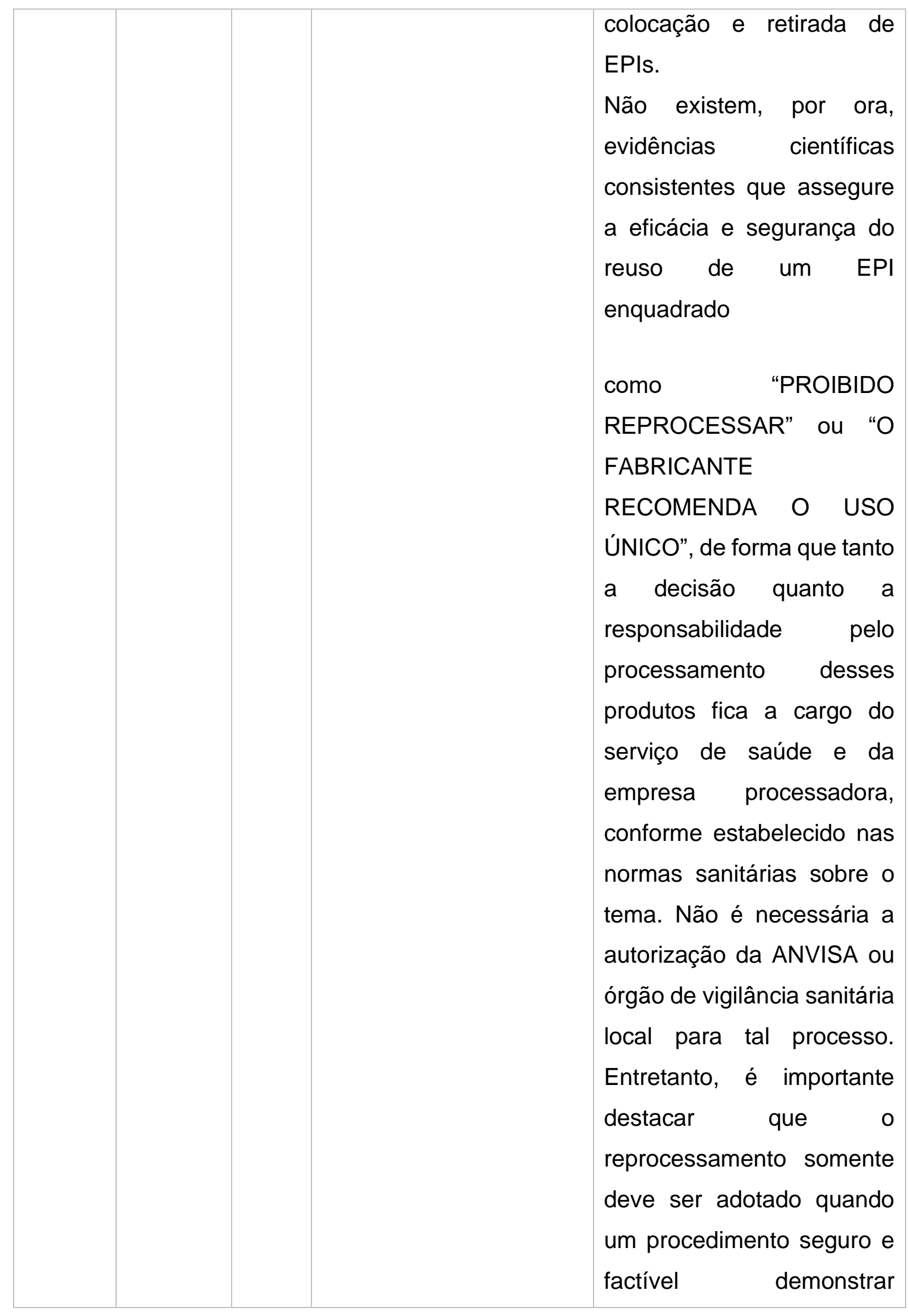




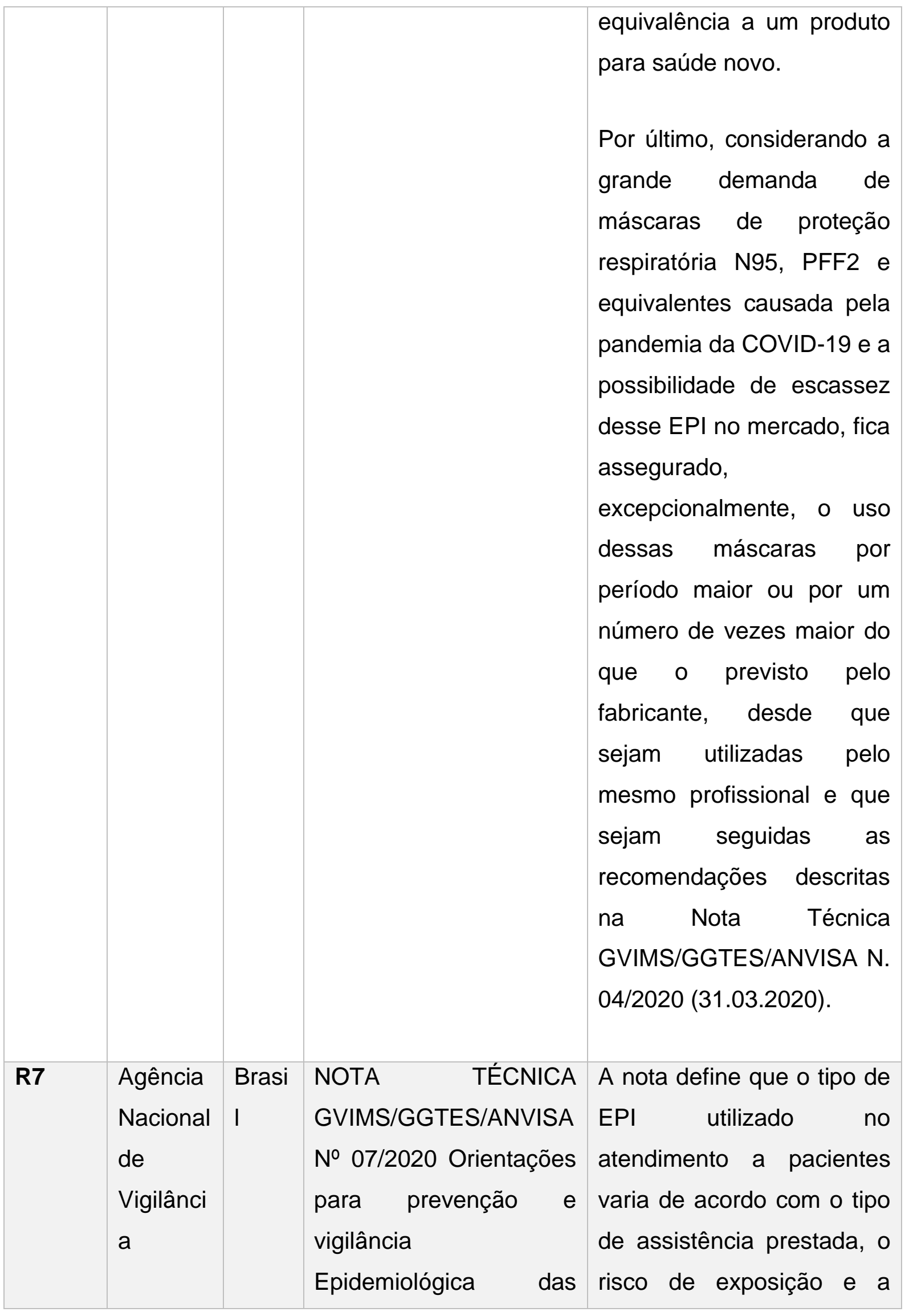




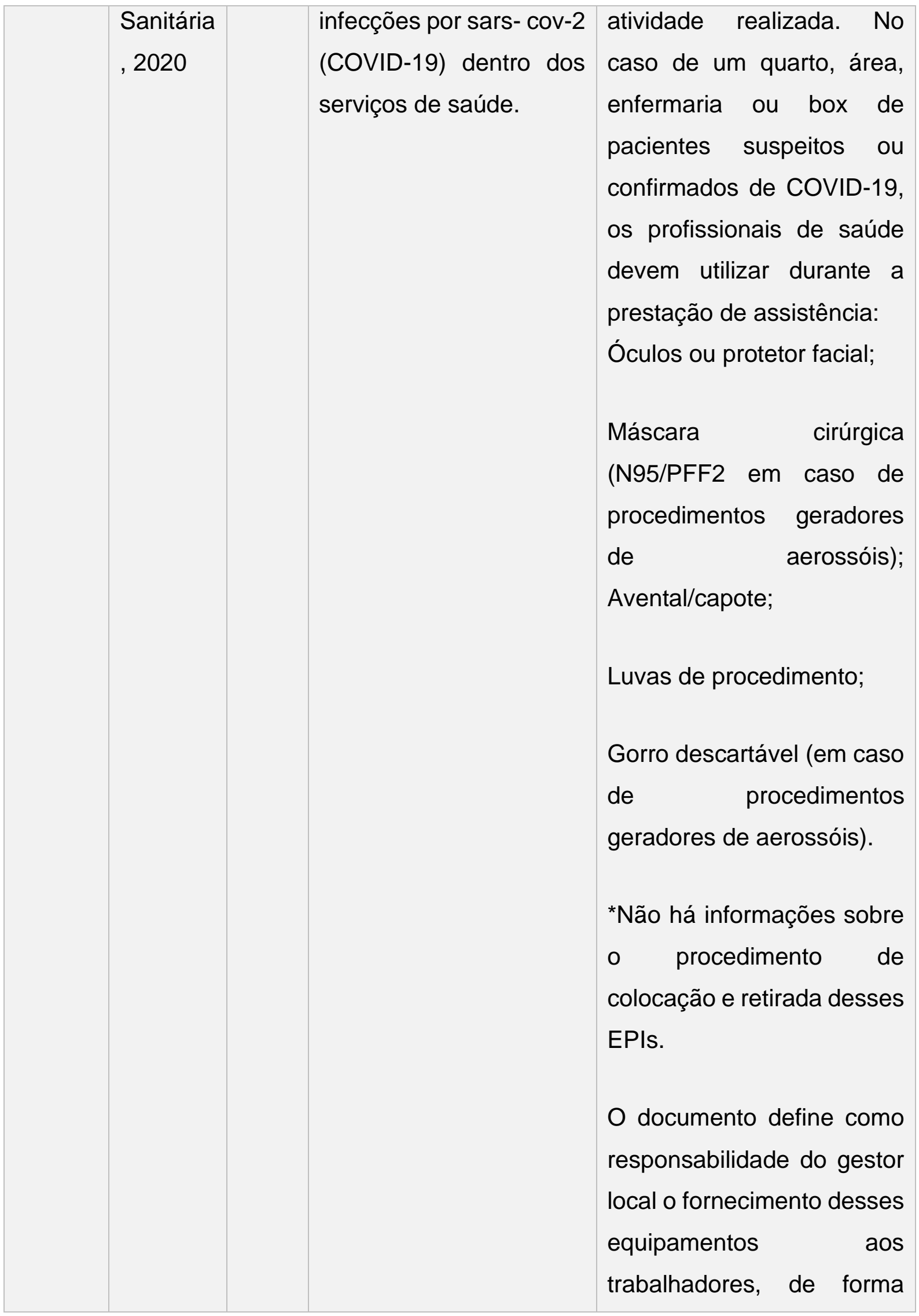




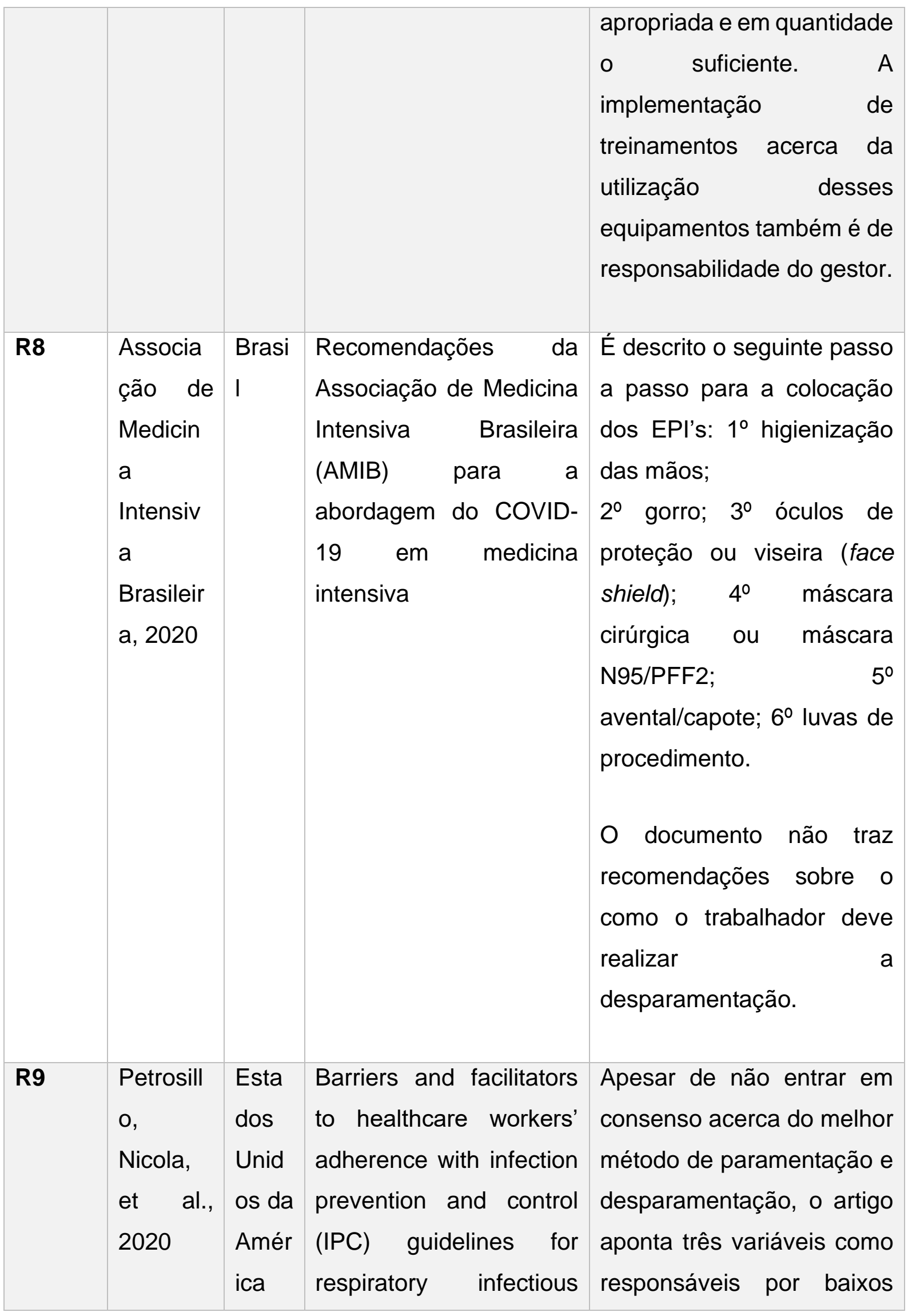




\begin{tabular}{|c|c|c|c|c|}
\hline & & & $\begin{array}{l}\text { diseases: a rapid } \\
\text { qualitative evidence } \\
\text { synthesis (Review) }\end{array}$ & $\begin{array}{l}\text { índices de adesão ao uso } \\
\text { correto de EPIs, sendo a } \\
\text { primeira variável a falta de } \\
\text { diretriz específica para a } \\
\text { COVID-19, em segundo a } \\
\text { não obrigatoriedade de } \\
\text { treinamento sobre o tema, e } \\
\text { por último a falta de } \\
\text { realização de avaliações de } \\
\text { desempenho na prática } \\
\text { desses profissionais. }\end{array}$ \\
\hline R10 & $\begin{array}{l}\text { Verbeek } \\
\text {, Jos H., } \\
\text { et al., } \\
2020\end{array}$ & $\begin{array}{l}\text { Esta } \\
\text { dos } \\
\text { Unid } \\
\text { os da } \\
\text { Amér } \\
\text { ica }\end{array}$ & $\begin{array}{l}\text { Personal protective } \\
\text { equipment for preventing } \\
\text { highly infectious } \\
\text { diseases due to } \\
\text { exposure to } \\
\text { contaminated body fluids } \\
\text { in healthcare staff } \\
\text { (Review) }\end{array}$ & $\begin{array}{l}\text { O artigo traz que as taxas } \\
\text { de contaminação do } \\
\text { profissional por fluídos } \\
\text { contaminados não são } \\
\text { determinadas apenas pelo } \\
\text { tipo de equipamento de } \\
\text { proteção individual, mas } \\
\text { também pelos } \\
\text { procedimentos de } \\
\text { colocação e retirada dos } \\
\text { mesmos. Associa ainda a } \\
\text { remoção inadequada } \\
\text { destes equipamentos com a } \\
\text { autocontaminação e um } \\
\text { maior risco de infecção. } \\
\text { *É necessário salientar que } \\
\text { a certeza das provas é } \\
\text { baixa a muito baixa porque } \\
\text { as conclusões se baseiam } \\
\text { em um ou dois pequenos }\end{array}$ \\
\hline
\end{tabular}




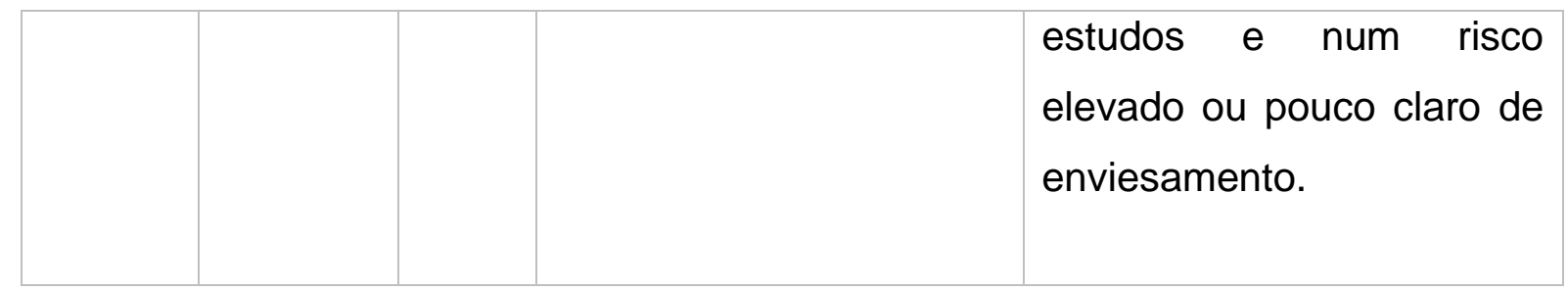

Fonte: As autoras, 2020

Todos os documentos foram publicados no ano de 2020 , sendo o R9 e R10 artigos e os demais documentos de origem de órgãos de saúde nacional e também internacional. São eles: a Agência Nacional de Vigilância Sanitária, Associação de Medicina Intensiva Brasileira, Centers for Disease Control and Prevention e World Health Organization. Merece ressaltar que os procedimentos de paramentação e desparamentação são técnicas conhecidas e executadas no cotidiano do exercício profissional. No entanto, esse tema representa preocupação de estudiosos no que se refere ao cuidado protetivo contra contaminação por micro-organismos nocivos à saúde, em especial o novo coronavírus. Isso pode ter mobilizado o interesse dos mesmos em realçar a relevância da temática, assim como o interesse de investigação desta pesquisa.

\section{DISCUSSÃO}

Os resultados obtidos evidenciaram destaques diversificados. Foram encontrados enfoques quanto aos EPIs (Equipamentos de Proteção Individual), e a respeito dos passos para a paramentação e desparamentação, enfoques que se constituíram em categorias para sistematizar a discussão dos resultados.

Ao compreender a relevância da temática para a segurança do profissional e do usuário nos serviços de saúde e no intuito de prevenir a contaminação neste caso, pelo coronavírus, percebeu-se a necessidade de realçar o(s) objetivo(s) proposto(s) no sentido de pontuar as divergências e similaridades nas orientações/determinações elencadas na literatura sobre os procedimentos de paramentação e desparamentação, para sumarizar o consenso de execução dos procedimentos mencionados, além de pontuar os demais enfoques encontrados nos textos 
levantados que constituem elevada importância. Diante do exposto passar-se-á a seguir focar nas categorias constituídas por esta investigação.

\section{CATEGORIA A EQUIPAMENTOS DE PROTEÇÃO INDIVIDUAL (EPIS)}

O EPI é usado para proteger o profissional de saúde de indivíduos infectados, superfícies, materiais e produtos potencialmente infecciosos, além de outras substâncias potencialmente perigosas usadas durante a prestação de assistência. Por isso, todo profissional deve receber capacitação e demonstrar capacidade de uso seguro desses equipamentos, sendo capaz de identificar quando e qual EPI é necessário para cada situação; como vesti-lo, usá-lo e retirá-lo adequadamente de maneira a evitar autocontaminação; como descartar ou desinfetar, como armazená-lo após o uso e quais são suas limitações (ANVISA, 2020a).

A maioria dos documentos utilizados neste estudo ( $R 1, R 2, R 3, R 4, R 9$ e R10) recomendam o uso dos seguintes EPIs pelo profissional que presta assistência a um paciente com suspeita ou confirmação de COVID-19:

- Respirador N95, PFF2 ou equivalentes (em caso de procedimentos geradores de aerossóis) ou máscara cirúrgica (demais procedimentos);

- Proteção ocular ou protetor facial;

- Luvas deprocedimento;

- Avental/capote.

A Agência Nacional de Vigilância Sanitária (R7) e a Associação de Medicina Intensiva Brasileira (R8) também recomendam estes equipamentos, entretanto, incluem o gorro descartável como EPI necessário. Não obstante a ANVISA o recomenda somente em caso de procedimentos capazes de gerar aerossóis, enquanto a AMIB propõe o uso em todos os procedimentos assistenciais, diante de pacientes suspeitos ou confirmados quanto a contaminação por COVID-19.

Devem ser realizadas algumas considerações acerca de alguns desses equipamentos: 


\section{MÁSCARA CIRÚRGICA}

Como parte dos esforços de controle de fonte e para proteção pessoal do profissional recomenda-se que o mesmo faça uso da máscara cirúrgica por todo o período de permanência no serviço de saúde. Em caso de escassez do equipamento, a prioridade de uso do EPI deve ser dada aos profissionais que prestam assistência ou possuem contato direto, a menos de 1 metro, com pacientes. Já os profissionais cujas funções no trabalho não exigem uso de EPI, como por exemplo, pessoal exclusivamente administrativo ou que atuam em áreas com contato maior que a 1 metro dos pacientes, estes devem utilizar máscaras de tecido enquanto estiverem na instituição, pois o controle de fonte será semelhante ao indicado para a população em geral (ANVISA,2020a).

\section{MÁSCARAS DE PROTEÇÃO RESPIRATÓRIA (RESPIRADOR PARTICULADO)}

São máscaras que possuem eficácia mínima na filtração (filtram 95\% de partículas de até $0,3 \mu \mathrm{M}$ ), são as do tipo N95, N99, N100, PFF2 ou PFF3. Devem ser utilizadas sempre que houver realização de procedimentos geradores de aerossóis como, por exemplo, intubação ou aspiração traqueal, ressuscitação cardiopulmonar e entre outros (AMIB, 2020). Contudo, casos esses modelos de máscaras sejam providos de válvula expiratória não deverão ser utilizados por profissionais, pelo motivo desse dispositivo filtrar o ar aspirado, mas permitir exalar o ar do profissional, assim na hipótese de estar infectado contaminaria o ambiente, outros profissionais e pacientes. Ocorre que em decorrência da perspectiva atual da pandemia de COVID-19 e da possibilidade de escassez de EPI, a máscara com válvula expiratória poderá ser usada se associada ao protetor facial. Essa medida de mitigação não deve ser aplicada em Centro Cirúrgico, pelo aumento do risco de contaminação da ferida operatória por meio de gotículas expelidas pelos profissionais (ANVISA, 2020a).

\section{PROTEÇÃO OCULAR OU PROTETOR FACIAL/FACE SHIELD}


O equipamento deve cobrir a frente e os lados do rosto e seu uso deve ser exclusivo por profissional (AMIB, 2020). Em caso de reutilização o equipamento deve ser limpo, desinfetado e acondicionado de acordo com as instruções de reprocessamento do fabricante (CDC, 2020a).

É necessário certificar-se de que o EPI é compatível com o respirador ou máscara utilizado, para que não haja interferência com o posicionamento correto da proteção para os olhos ou com o encaixe/vedação do respirador ou máscara. Os óculos de proteção com espaços entre os óculos e o rosto provavelmente não protegem os olhos de todos os respingos e borrifos (CDC, 2020a).

\section{LUVAS DE PROCEDIMENTO}

Devem ser utilizadas quando houver risco de contato das mãos do profissional com sangue, fluidos corporais, excreções, mucosas, secreções, pele não íntegra e artigos ou equipamentos contaminados, de forma a reduzir a possibilidade de transmissão do novo coronavírus para o trabalhador de saúde, assim como de paciente para paciente por meio das mãos do profissional (AMIB, 2020).

\section{AVENTAL/CAPOTE}

O equipamento deve ser impermeável e utilizado durante procedimentos com risco de respingos de sangue, fluidos corpóreos, secreções e excreções, e outras situações que podem resultar na contaminação da pele e roupa do profissional (AMIB, 2020).

É recomendado que o avental/capote tenha mangas longas, punho de malha ou elástico e abertura posterior, e seja capaz de proporcionar uma barreira antimicrobiana efetiva (AMIB, 2020). Entretanto, é valido salientar que a cobertura de mais partes do corpo leva a uma melhor proteção, mas geralmente dificulta os procedimentos de colocação e retirada, além de reduzir o conforto do utilizador, podendo então elevar os riscos de contaminação (VERBEEK et al, 2020). 
Com relação ao processo de trabalho, o serviço de saúde deve desenvolver estratégias que busquem minimizar a necessidade do uso de equipamentos de proteção individual, lançando mão, por exemplo, da telemedicina para avaliação inicial de pacientes suspeitos, redução do número de profissionais nas áreas de risco, simplificação do fluxo de trabalho e entre outras (WHO, 2020b).

Além disso, também cabe ao serviço definir e descrever as políticas e os procedimentos relacionados a sequência segura de colocação e retirada dos EPIs, uso prolongado e/ou reprocessamento dos mesmos, além do processo de limpeza, desinfecção e forma de acondicionamento entre os usos. Essas responsabilidades foram evidenciadas em 03 (três) dos documentos analisados (R4, R6 e R7). As recomendações dos órgãos de saúde e as evidências científicas atuais devem ser utilizadas como base para a definição desses procedimentos (CDC, 2020a).

\section{CATEGORIA B PARAMENTAÇÃO E DESPARAMENTAÇÃO - SIMILARIDADES E DIVERGÊNCIAS ENCONTRADAS NOS PROCEDIMENTOS}

Esta categoria foi centrada no foco do primeiro objetivo proposto. Diante dos resultados obtidos neste estudo foi necessário desmembrar a categoria em três partes constituindo-se em sub categorias para a compreensão das especificidades que cabem a cada um dos procedimentos. A primeira parte focou a similaridade de passos para a paramentação, seguida pela segunda parte ocupada pela divergência dos mesmos. A terceira parte limitou-se a identificar as similaridades dos passos para a desparamentação. Uma vez não identificados divergências para a desparamentação, a discussão dos dados obtidos permaneceu no limite das três sub categorias assinaladas.

\section{SUB CATEGORIA B.I) SIMILARIDADES DE PASSOS PARA A PARAMENTAÇÃO}


No que diz respeito a como o profissional deve realizar a paramentação duas das publicações (R1 e R3) possuem recomendações similares e orientam a seguinte ordem de colocação dos EPIs:

1. Avental/ capote;

2. Máscara cirúrgica ouN95/PFF2;

3. Face shield/protetor facial ou óculos deproteção;

4. Luvas.

Além disso, ambas destacam como necessária a realização da higiene das mãos, com álcool $70 \%$ ou água e sabão, antes de iniciar o processo de paramentação.

A referência identificada como R4 não aponta uma ordem específica para a paramentação apenas determina os equipamentos que devem ser colocados antes da entrada no quarto do paciente ou área de cuidados, sendo eles: respirador (N95, PFF2 ou equivalentes) ou máscara cirúrgica, proteção ocular/protetor facial e avental/capote. As luvas de procedimento devem ser colocadas ao entrar no quarto ou área de cuidados.

\section{SUB CATEGORIA B.II) DIVERGÊNCIAS DE PASSOS PARA A PARAMENTAÇÃO}

Já a referência identificada como $\mathrm{R} 8$, apresenta uma divergência com relação sequência de paramentação, a mesma propõe a seguinte ordem:

1. Gorro;

2. Óculos de proteção ou viseira (face shield);

3. Máscara cirúrgica ou máscaraN95/PFF2;

4. Avental/capote;

5. Luvas deprocedimento.

A necessidade da higiene das mãos antes de realizar a colocação dos equipamentos também é evidenciada pelo documento. 


\section{SUB CATEGORIA C.III) SIMILARIDADES DE PASSOS PARA A DESPARAMENTAÇÃO}

O uso inadequado ou excessivo dos EPls gera um impacto adicional na escassez de suprimentos e no risco de contaminação do profissional principalmente no momento da desparamentação. Por isso, este processo deve ser descrito apriori no intuito de permitir a realização de treinamentos e solução de possíveis dúvidas (ANVISA, 2020a).

Apenas as referências R1 e R3 definem uma ordem similar para a retirada dos equipamentos de proteção individual, que é a seguinte:

1. Luvas;

2. Avental/capote;

3. Proteção facial ou óculos deproteção;

4. Máscara cirúrgica ouN95/PFF2.

Ao comparar os riscos de contaminação de se retirar o capote/avental e a luva em um único passo versus retirar a luva e em seguida o capote/avental, um estudo evidenciou um menor índice de contaminação na última técnica (VERBEEK et al, 2020).

Agora com relação aos momentos em que cada equipamento deve ser retirado, as referências R1 e R4, orientam que o profissional deve retirar as luvas e o capote/avental antes da saída do quarto ou área de cuidados, realizando a higiene das mãos em seguida. E somente após sair do ambiente, deve retirar o respirador ou máscara e a proteção ocular/protetor facial, prosseguindo novamente com higiene das mãos.

Durante a remoção da máscara, o profissional deve estar atento para realizar a retirada por meio das tiras, evitando tocar no equipamento. E na remoção do avental/capote deve certificar-se de realizar o movimento de maneira gentil, puxando 
cuidadosamente o EPI para baixo e longe do corpo. Essas orientações foram melhor destacadas nas referências $\mathrm{R} 1$ e R3.

\section{CONSIDERAÇÕES FINAIS}

No que tange a biossegurança dos profissionais de saúde que prestam assistência à pacientes com suspeita e/ou confirmação de infecção pelo novo coronavírus os equipamentos de proteção individual são considerados imprescindíveis. Embora o uso de vestuário composto por avental, gorro, máscara, óculos e luvas, ser traje comum em espaços cirúrgicos e em outros serviços que assistem pessoas portadoras de doenças transmissíveis, e ainda serem temáticas de ensino e aprendizado inseridos no currículo acadêmico, houve preocupação de estudiosos em destacar os equipamentos de proteção individual e a sequência dos procedimentos para a paramentação e desparamentação decorrente do atual cenário sanitário mundial.

Pensando nisso, este estudo buscou identificar as divergências e similaridades acerca dos procedimentos de paramentação e desparamentação do profissional de saúde, e ao final, sumarizar o consenso para realização dos procedimentos mencionados com base nos textos selecionados para a revisão integrativa, os quais foram significativos para obtenção dos resultados de onde foram originadas as contribuições deste estudo.

O profissional de saúde prestador de assistência à pacientes suspeitos ou confirmados de COVID-19 deve utilizar esses equipamentos de proteção individual: máscara cirúrgica ou N95/PFF2 ou equivalente; proteção ocular ou protetor facial (face shield); luvas de procedimento; avental/capote. Alguns autores recomendam também o gorro descartável como EPI essencial e se disponível deve ser utilizado.

Pensando na praticidade para o processo de colocação e retirada dos EPIs e considerando todas as recomendações analisadas durante este estudo, criou - se o seguinte procedimento operacional padrão para a paramentação e desparamentação do profissional de saúde: 


\section{Paramentação}

1ำ passo: higiene das mãos com álcool ou água e sabão; 2ํำ passo: colocação do avental/capote;

$3^{\circ}$ passo: colocação da máscara cirúrgica ou N95/PFF2 ou equivalentes; $4^{\circ}$ passo: colocação da touca descartável;

50 passo: colocação da proteção ocular ou protetor facial (face shield) - a escolha do equipamento deve considerar a máscara utilizada;

60 passo: colocação das luvas de procedimento.

É importante destacar que a paramentação deve ocorrer antes da entrada na área de cuidados e/ou quarto do paciente, apenas as luvas podem ser colocadas já dentro do ambiente.

\section{Desparamentação}

1ํ passo: retirada e descarte da luva de procedimento;

$2^{\circ}$ passo: retirada e descarte do avental/capote - os nós ou botões devem ser soltos e o avental puxado pelo ombro, de forma gentil, para baixo e longe do corpo;

Esses dois primeiros passos devem ser realizados dentro da área de cuidados e/ou quarto do paciente, e ao final o profissional pode deixar o ambiente.

$3^{\circ}$ passo: higiene das mãos com água e sabão;

$4^{\circ}$ passo: retirada dos óculos de proteção ou protetor facial (face shield) - deve ser retirado pelas alças e puxado para frente e para cima, a frente do equipamento não deve ser tocada. Em caso de reutilização e/ou uso prolongado o equipamento deve ser higienizado e acondicionado conforme protocolo da instituição; 
5o passo: retirada e descarte do gorro descartável;

$6^{\circ}$ passo: retirada e descarte da máscara cirúrgica ou N95/PFF2 ou equivalentes - a remoção deve ser realizada através das alças, nunca tocando a parte frontal da máscara;

$7^{\circ}$ passo: higiene das mãos com álcool $70 \%$ ou água e sabão.

Novos estudos devem ser realizados à luz do tópico uma vez que se trata de um tema atual, com grande rotatividade de informações e de relevância para a saúde. No plano sanitário, fica de proposta deste estudo para uma futura pesquisa, investigar em tempo real, o comportamento do profissional de saúde ao realizar as técnicas de paramentação e desparamentação com a finalidade de vigilância para a segurança no trabalho.

\section{REFERÊNCIAS}

AMIB, Associação de Medicina Intensiva Brasileira. Recomendações da Associação de Medicina Intensiva Brasileira para a abordagem do COVID-19 em medicina intensiva. Disponível em: https://www.amib.org.br/fileadmin/user_upload/amib/2020/junho/10/Recomendacoes _AMIB-3a_atual.-10.06.pdf Acesso em: 21 set. 2020.

ANVISA ADM. Orientações para prevenção e vigilância epidemiológica das infecções por SARS- CoV-2 (COVID-19) dentro dos serviços de saúde NOTA TÉCNICA GVIMS/GGTES/ANVISA No07/2020-

Atualizadaem17/09/2020.Anvisa.gov.br.2020a.Disponívelem:

$<$ https://www20.anvisa.gov.br/segurancadopaciente/index.php/alertas/item/nota-

tecnica-gvims-ggtes-

anvisa-n-07-2020-atualizada-em-17-092020?category_id=244>. Acesso em: 21 set. 2020.

ANVISA, Agência Nacional de Vigilância Sanitária. Nota técnica sobre o processamento (reprocessamento) de Equipamentos de Proteção Individual No 
12/2020/SEI/GGTES/DIRE1/ANVISA.

[s.I.:

s.n.,

s.d.]. Disponívelem:

$<$ https://portaldeboaspraticas.iff.fiocruz.br/wp-content/uploads/2020/05/Nota-Tecnica12- GGTES.pdf>. Acesso em: 21 set. 2020.

BRASIL; Ministério da Saúde - MS, Secretaria de Vigilância em Saúde. (2020). Boletim epidemiológico especial: doença pelo Coronavírus COVID-19 semana epidemiológica $36 \quad(30 / 08$ a 05/09). Disponível em: https://www.gov.br/saude/pt-br/Coronavirus/boletins-epidemiologicos- $1 /$ set/boletimepidemiologico-covid-30.pdf Acesso em: 11 set. 2020.

CDC. Interim Additional Guidance for Infection Prevention and Control Recommendations for Patients with Suspected or Confirmed COVID-19 in Outpatient Hemodialysis Facilities. 2020a. Centers for Disease Control and Prevention. Acesso em: 31 ago. 2020.

CDC. Using Personal Protective Equipment (PPE). 2020b. Centers for Disease Control and Prevention. Disponível em: <https://www.cdc.gov/coronavirus/2019ncov/hcp/using-ppe.html>. Acesso em: 31 ago. 2020.

CDC. COVID-19: Operational Considerations for Non-US Settings. 2020c. Centers for Disease Control and Prevention. Disponível em: $<$ https://www.cdc.gov/coronavirus/2019-ncov/hcp/non-us- settings/public-healthmanagement-hcw-exposed.html>. Acesso em: 27 ago. 2020.

COFEN, Conselho Federal de Enfermagem (2020). Profissionais infectados com COVID-19. Disponível em: http://observatoriodaenfermagem.cofen.gov.br/ Acesso em: 11 set. 2020.

GALVÃO, Taís Freire; PANSANI, Thais de Souza Andrade; HARRAD, David. Principais itens para relatar Revisões sistemáticas e Meta-análises: A recomendação PRISMA. Epidemiologia e Serviços de Saúde, 2015, 24: 335-342. 
HOUGHTON, Catherine; MESKELL, Pauline; DELANEY, Hannah; et al. Barriers and facilitators to healthcare workers' adherence with infection prevention and control (IPC) guidelines for respiratory infectious diseases: a rapid qualitative evidence synthesis. Cochrane Database of Systematic Reviews, 2020.

OMS, Organização Mundial da Saúde; OPAS, Organização Pan-Americana da Saúde. Folha informativa COVID-19. Disponível em: https://www.paho.org/pt Acesso em 9 out 2020.

TAVARES DE SOUZA, Marcela; DIAS DA SILVA, Michelly; DE CARVALHO, Rachel. Revisão integrativa: o que é e como fazer Integrative review: what is it? How to do it? v. 8, n. 1, p. 102-108, 2010. Disponível em: $<\mathrm{https}: / /$ www.scielo.br/pdf/eins/v8n1/pt_1679-4508-eins-8-1-0102.pdf>. Acesso em: 11 out. 2020.

VELAVAN, Thirumalaisamy P.; MEYER, Christian G. The COVID-19 epidemic. Tropical Medicine \& International Health, v. 25, n. 3, p. 278-280, 2020. Disponível em: <https://onlinelibrary.wiley.com/doi/full/10.1111/tmi.13383>. Acesso em: 5 Nov. 2020.

VERBEEK, Jos H; RAJAMAKI, Blair; IJAZ, Sharea; et al. Personal protective equipment for preventing highly infectious diseases due to exposure to contaminated body fluids in healthcare staff. Cochrane Database of Systematic Reviews,2020.

WORLD HEALTH ORGANIZATION. How to put on and take off personal protective equipment (PPE). Who.int, 2020a.

WORLD HEALTH ORGANIZATION. Rational use of personal protective equipment for coronavirus disease (COVID-19) and considerations during severe shortages: interim guidance, 6 April 2020. Who.int,2020b

Enviado: Novembro, 2020. 
Aprovado: Dezembro, 2020. 